\title{
A Mental Health Clinician's View of Cultural Competence Training
}

\author{
Robert E. Drake
}

Published online: 2 April 2013

(C) Springer Science+Business Media New York 2013

Let me first congratulate the authors on excellent contributions to a relatively unsettled and unsettling area. Most clinicians and faculty members accept that we should be practicing and teaching cultural competence, but how should it be done? These papers add considerable substance to a field dominated by platitudes. While illuminating many of the consternating dilemmas, the authors are remarkably forthright about the mixed results of sincere efforts to teach cultural competence. Should we focus on specific cultures, on unique individuals, on the clinician's biases, or on the system? As the U.S. speeds toward diversity and multiculturalism, these issues require extensive exploration. We are fortunate to have the current authors as intrepid guides.

For this commentary, I have been asked to consider some of my own experiences as a practicing psychologist, psychiatrist, and services researcher over the past four decades. Tolstoy described his life as one of obsessional devotion to work and duty interrupted by rare emotional epiphanies, such as the birth of a child, which profoundly changed his understanding of people, relationships, and meaning. So it has been with my understanding of cultural competence and mental health. In the following, I describe some of the moments of awareness.

As a young person growing up in rural Florida, I never encountered African Americans in the segregated schools I attended but worked with them during the summers on farms. I was often shocked to hear about their lives, dominated as they were by poverty, lack of opportunity, and general resignation to American Apartheid. Later at college in the Northeast, I encountered race riots that left the inner cities all around our small college in flames. My African-American classmates shunned those of us who were white. In addition to these shock waves, the feminist movement, the anti-war protests of the $60 \mathrm{~s}$, and the entitlement of Ivy League elitism-all surrounding me daily-were equally foreign. None of these quite

R. E. Drake ( ()

Dartmouth Psychiatric Research Center, Lebanon, NH, USA

e-mail: Robert.E.Drake@Dartmouth.edu 
computed in my immature, science-focused brain. Unable to integrate these challenges, I hid in the chemistry lab.

Later, I had the opportunity to explore these enigmas during graduate training in North Carolina for 8 years. Several personal experiences again disturbed my equilibrium: working with African-American families and classmates in the hospital, volunteering for several years in the state mental hospital, and volunteering at the YMCA and a public housing project. At the university, nothing in the curriculum touched on issues of culture, race, ethnicity, or class despite the fact that we served a diverse group of African-American, Native-American, and poor, rural patients. The culture of my own clinical training was decidedly "monocultural" (Llerena-Quinn, this issue), and my African-American classmates were bright but obviously overwhelmed by the white culture of the medical center. Although the official curriculum of my eight years of clinical education did not address ethnicity, race, or culture, I found myself embracing the "hidden curriculum" (Llerena-Quinn, this issue) to learn from the experiences of interacting with diverse patients and in my daily encounters in the community.

The African-American and Native-American patients, I saw during my training, always seemed surprised when we took their struggles so seriously. Perhaps they were accustomed to brief visits with more senior clinicians. As doctors-in-training, however, we were assigned to only a few patients at a time, and therefore had time to listen, to ask questions, and to learn about our patients' experiences. I am certain that we benefitted more than they did from the extra time. The relationships were profoundly educational. I remember painfully a young child, treated for months with herbs by an indigenous healer whom the family trusted, and subsequently brought to the hospital only after it was too late for medical care to save her.

On another occasion, working in an outlying general medical clinic that was $99 \%$ African American, I attended a discussion on family violence. An expert from New York was lecturing on the problem and offering advice: strongly emphasizing separating the women and children from their abusive partners. At the end of her talk, one of the senior nurses spoke up and said essentially that all of the staff and patients at this clinic, including herself, were involved in physical altercations with their partners, and that the speaker had no understanding whatsoever of their culture and should go back to New York to pontificate. What a shock both of these experiences gave me! I had never heard about indigenous healers or spousal violence and would have guessed that both phenomena were exceedingly rare. How could they be normative and yet never mentioned in my experience and medical education? Families and nurses patiently extended my education over several years.

My experience at the state hospital was similarly disturbing. I began without any understanding of the culture of mental illness and public hospitals. The doctors at the state hospital typically came from other countries, spoke English poorly, and were of little help to my learning. The nurses and ward attendants, however, came from the same small towns, families, and cultures as the patients. They explained how stigmatized and debilitating life was for people with mental illnesses in these small towns. The patients themselves shocked me into further cultural awareness. As a volunteer, I often came to the state hospital in the afternoon and stayed until late in the evening, observing, playing games, and talking with people, trying to 
understand what it was like to live with a mental illness. During the days, patients' behaviors generally accorded with what I read in textbooks: people shuffled about, sometimes shouting out and hallucinating, and often not responding coherently. But in the evenings, when there were essentially no staff members on the long-term wards, the patients' behaviors and conversations transformed unexpectedly. Many who trudged slowly around the hospital, essentially non-verbal during the days, suddenly began talking and acting like different people in the evenings. They opened the trunks below their beds, pulled out radios, board games, playing cards, and magazines. They talked, joked, played games, flirted, and met privately with intimate partners. What was this about? As I got to know the patients, observing their leaving and returning to the hospital, listening to their stories about life outside the hospital, I began to understand why they had two ways of presenting themselves and why many chose the hospital as a place to live. While not acknowledging their own dissimulations, many patients were able to describe the typical impression management games in terms of how they observed others' behaviors.

My experience as a volunteer at a YMCA and a public housing project offered another profound experience in encountering cultural difference. On the baseball field, racial divides between African-American and white children seemed to dissipate easily as they played together. I grew to know these children and their families as their mothers warmly took me into their apartments, fed me well, took me to church with them, and told me about their lives. Slowly, I began to realize how difficult their lives were: the grinding poverty, the demeaning work as maids, the regrets over their own lack of education, the difficulty with their children's schools that were geared for two-parent households in which adults could attend day-time meetings, the inability to control their adolescent sons, and the unreliable and sometimes violent men moving in and out of the housing project at night. The mounting despair of the kids became apparent over time, as I watched these delightful, positive, pro-social kids become completely estranged from the public schools and drift into dangerous lifestyles. The common joke of referring to the local school as "Hopeless Valley" rather than Hope Valley turned to tragedy as they became involved with drugs and crime; one after another has been killed violently, died of AIDS, or become incarcerated. I was experiencing first-hand what Robert Coles described in his Pulitzer Prize-winning series, Children of Crisis.

During my psychiatry training in Boston, we had one seminar on cultural competence. I remember it distinctly because most of the residents came late, just after the professor left in a huff. So much for multicultural training in a health system that required translators for the 33 languages our patients spoke! The work itself, however, was truly an education. The case management teams that I worked with during and after residency were staffed by wonderful young people from many of the same cultural backgrounds as our patients. In addition to their case management roles, they served as culture brokers: patiently translating the language and cultural beliefs, involving families and communities, and explaining to the naïve doctors such as myself what was happening. I slowly learned something about various ethno-racial groups and also about the cultures of drug addiction, poverty, and homelessness. Patients I worked with for years were evicted from their housing, shot by the police, jumped to their deaths, or died as a result of poor medical care. 
The stigma against people with serious mental illness, especially those from minority cultures, was a daily reality as I attended meetings with families, housing and Social Security authorities, lawyers, and judges. I gave patients my phone number and told them, "If you are having bad trouble, please give me a call." People rarely abused the offer, but I often received phone calls from emergency room doctors who said things like, "Dr. Drake, I have this 'dirt bag' in my emergency room and he claims he knows you." One lesson I took from the experience was the importance of the culture brokers-people who could easily travel between the worlds of middle class white medicine and impoverished immigrants with mental disorders. Without these culture brokers, we could never have understood the behaviors of many of our patients. Fortunately, discussions of different cultures-e.g., Portuguese, Haitian, mentally ill, drug-abusing, homeless, gay, and many others-enriched our daily team meetings. The challenge of respecting and understanding dialog and experience was, as Laurence Kirmeyer explains in his thoughtful essay, an unending challenge.

When I came to New Hampshire and began to transition to mental health services research, I was committed to trying to understand people's phenomenological experiences and observing their behaviors closely in social, environmental, economic, and cultural contexts. For more than 20 years, my anthropology colleagues, Hoyt Alverson, Rob Whitley, and Elizabeth Carpenter-Song, have added ethnographic and other qualitative methods to our quantitative research. Their work has elucidated numerous perplexing findings. To cite just a few examples, they discovered that many participants relapsed to drug abuse because of hidden PTSD symptoms that emerged when they stopped using drugs; that many participants in vocational studies who perplexed us by not working were actually working informally or illegally (and did not report such income to authorities, clinicians, or research interviewers); and that many Latino participants deferred to family members before making any treatment decisions. Without the help of anthropologists, we would have missed many insights that improved care.

So what has my clinical experience taught me about cultural competence training? I believe the standard view of mental health clinicians is that culture is just one personal attribute among many others. A clinician strives, one patient at a time, to understand the unique combination of attributes of each individual. One patient is a young gay man attempting to develop his identity in the context of an unaccepting family, a conservative religion, and an ethnic community that rejects homosexuality. The next patient is an elderly man, struggling with loss of status and virility in a familial and ethnic culture that derogates his anxiety as inappropriate. And other unique individuals follow all day. The clinician, in order to be helpful, tries to understand each one's phenomenological experience and sociocultural environment. This view often falls short, however, because culture is more than what an individual acknowledges or recognizes. Profound influences occur outside the realm of consciousness and verbal expression, and the mental health clinician must strive constantly to understand them. Working in teams with culture brokers can help, as I have indicated. Curiosity, openness, and empathy are essential, and education might also play a part. Clinicians also need to understand that what appear to be individual 
characteristics, attributes, or traits may also reflect deep cultural histories, which may include mistrust, legacies of oppression, and even genocide.

I began by saying that emotional experiences have often punctuated my obsessional nature. Part of the challenge of trying to understand other people and cultures has always been to understand my own strong internal reactions to and prejudices regarding others' experiences. When do generational guilt regarding slavery, the desire to rescue children from adversity, or inability to comprehend others' dreadful and sometimes gruesome experiences overwhelm and distort one's ability to listen empathically and respond appropriately? Understanding one's internal reactions is another unending venture, often motivating the need for years of clinical supervision and personal therapy. Most mental health professionals pursue these experiences, which have helped me enormously. But how often are they attuned to cultural awareness? Certainly supervisors and therapists who think about cultural issues could improve these experiences. As our society rapidly becomes more diverse and multicultural, we will need much greater attention to such issues. 